\title{
On the Mesoscale Variability Observed in the North Atlantic by Satellite Altimeters
}

\author{
Ye. A. Kulikov \\ State Oceanography Institute, Moscow
}

\author{
A. N. Zueva \\ Topographic Service, Russia, Moscow
}

\begin{abstract}
Soviet altimetry data, disclosed recently, are applied to describe mesoscale sea-level variability in the North Atlantic. The method of satellite data processing is presented and possible errors are estimated. Variations of sea surface heights measured by several altimeters in non-repeat orbits during a period of 4 years are used to compute the wave number spectra of mesoscale variability for ascendant and descendant satellite tracks. The instrument noise level (about $0.5-0.6 \mathrm{~m}^{2}$ ) has limited the resulting oceanic spectrum to wavelengths longer than $200-300 \mathrm{~km}$. The radius of correlation for the ascendant tracks is $200 \mathrm{~km}$ and differs from the one for descendant tracks, which is $300 \mathrm{~km}$. The ascendant tracks are directed nearly along the main current and corresponding along-track wavenumber spectrum is similar to spectra typical for highenergy ocean areas. It has a broad spectral 'bump' for wave lengths $500-1000 \mathrm{~km}$. The descendant tracks are directed across the current, the spectrum is smooth and similar to spectra in low-energy ocean areas. This difference demonstrates the strongly anisotropic character of mesoscale variability in the region of the Gulf Stream, where the frontal zone plays the role of a specific waveguide for high-energetic trapped quasi-geostrophic waves, propagating along the front.
\end{abstract}

\section{INTRODUCTION}

The development of the satellite remote-sensing methods opened wide possibilities to oceanographers to study large- and mesoscale variabilities in the World Ocean. In particular, the appearance of the satellite altimeter information $[1,2,3]$ for the first time made it possible to examine deformations of the sea surface in the open ocean, not by indirect data (using the dynamic method for hydrological intersections) but directly by measurements of the satellite heights above the earth (sea) surface. One should not overestimate the importance of these measurements as they made it possible to evaluate spatial variabilities of the sea level in the scale band from 10 to $1000 \mathrm{~km}$. This interval is typical to processes related to large- and mesoscale variabilities of the ocean currents.
The first measurements of satellite altimetry were stimulated by military purposes. One of the targets of these measurements was to determine the anomalies of the Earth gravity field and to specify the form of the geoid $[2,4]$. The sea level variations due to the ocean dynamics were interpreted at that time as random or systematic (in case of mean ocean currents) measurement errors. However, with the accumulation of information it became clear that these data may be successfully used for direct oceanographic investigations.

Initially the accuracy of sea level measurements had not exceeded $50 \mathrm{~cm} \mathrm{[3].} \mathrm{However,} \mathrm{it} \mathrm{was} \mathrm{enough} \mathrm{not} \mathrm{only}$ to distinguish the isolated sea level anomalies, related mainly to strong ocean boundary currents (like Gulf Stream or Kuroshio) or to the contrast frontal zones, but also to study the mesoscale variability of the ocean level. For example the SEASAT information showed the evident differences of wave number sea level spectra in high-energy frontal zones and in low-energy interior areas [5].

The SEASAT was the first satellite destined specially for oceanographical research. Ye. A. Kulikov, one of the authors of this paper, personally participated in implementation of hydrological transections in the Kuroshio zone along the SEASAT tracks which were made during the Second Soviet-American Tsunami Expedition (1978) for comparative analysis with SEASAT data and calibration of satellite altimetry measurements $[6]$. The corresponding results were published in [7] but without any mentions of the Tsunami Expedition or participants of the experiment, neither Soviets, nor Americans. Dr. R. R. Harvey, JIMAR, Honolulu, who lead this experiment, tragically was lost at sea in December, 1978, during "Holo-Holo" accident.

For many years altimetry observations from the USSR satellites were inaccessible to oceanographers. Since the altimetry data is no longer classified as military information, it is now possible to use a part of these data for scientific purposes in the ocean study.

The list of satellites with the data now available for analysis is presented in Table 1.
0-7803-1385-2/93/\$3.00 ${ }^{\text {C }} 1993$ IEEE U.S. Government work not protected by U.S. copyright 
TABLE 1

PARAMETERS OF SOME SATEILUITE WTTH ALTTMETER SYSTEMS

\begin{tabular}{|c|c|c|c|c|c|}
\hline Satellite & $\begin{array}{c}\text { Begin- } \\
\text { ning of } \\
\text { observa- } \\
\text { tions }\end{array}$ & $\begin{array}{c}\text { Apogee } \\
\text { height, km }\end{array}$ & $\begin{array}{c}\text { Perigee } \\
\text { height, km }\end{array}$ & $\begin{array}{c}\text { Inclina- } \\
\text { tion, de- } \\
\text { gree }\end{array}$ & $\begin{array}{c}\text { Period, } \\
\text { min }\end{array}$ \\
\hline $\begin{array}{c}\text { Kosmos- } \\
1950\end{array}$ & 5.30 .88 & 1534 & 1503 & 73.6 & 1.16 .0 \\
\hline $\begin{array}{c}\text { Kosmos- } \\
2037\end{array}$ & 8.28 .89 & 1537 & 1502 & 73.6 & 116.1 \\
\hline $\begin{array}{c}\text { Kosmos- } \\
2088\end{array}$ & 7.30 .90 & 1537 & 1502 & 73.6 & 116.0 \\
\hline
\end{tabular}

\section{DATA ANALYSIS}

The hydrodynamical signal $\left(h_{m}\right)$ was detected from the altimetry data according to:

$$
h_{m}=h_{r}-h_{g}-\left(h_{s}+h_{p}\right)+h_{t}
$$

where $h_{r}$ is the raw height of the satellite above the reference ellipsoid; $h_{s}$ is the raw height of the satellite above the sea surface as determined by altimeter; $h_{p}$ is the ionospheric and tropospheric path length correction; $h_{t}$ is the correction on tides, based on the Schwiderski's model [8-10]; $h_{g}$ is the height of geoid, using model of $0.25^{\circ}$ resolution based on SEASAT data. Unfortunately the American information on SEASAT is still classified, but this information is possible to obtain from Russian sources [11].

The KOSMOS altimetry data have a certain advantage in comparison to SEASAT and GEOSAT, since the KOSMOS satellite tracks are being done by non-repeat orbits which uniformly cover the region. This is better for spatial statistical oceanographical study. To eliminate residual orbital errors and large-scale geoid errors we have subtracted the mean value, estimated for each track.

The mesoscale sea level variability statistically may be described best by the spatial autocovariance function $C\left(r_{x}, r_{y}\right)$ or by the wavenumber spectrum $S\left(k_{x}, k_{y}\right)$, where $r_{x}, r_{y}$ are the spatial abscissa and ordinate displacements, $k_{x}, k_{y}$ are the components of wavenumber vector, corresponding to wave constituents of ocean field. To obtain such characteristics you ought to have synchronous data describing the sea surface deviations from the equilibrium level or, to be more exact, from the multiyear mean sea level. In case of the altimetry information one can speak of the synchronous observations only within one track, crossing the region under study. For the limited region these tracks in fact are parallel lines of the two types related to ascending and descending tracks

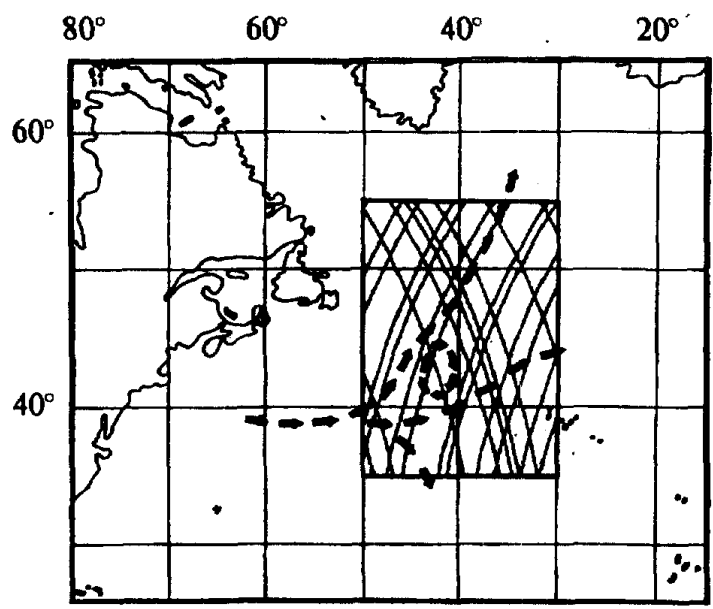

Fig. 1. The region under study. Lines related to the ascending and descending satellite Kosmos 1950 tracks. Arrows show the main branches of the Gulf Stream

(Fig. 1). Thus, to estimate the spatial spectrum of the sea level, you need to use either synchronous data from two different directions or asynchronous data from one direction with following recalculation of spatially-temporary into spatial characteristics only. The first way is much easier and, what is the most important, it does not require the use additional assumptions about qualities of the stochastic field, i.e. the ocean surface.

In the present paper the authors used along-track computations of spatial autocovariance functions. Fig. 2 shows these functions averaged for great number of tracks, crossing the region under study, for ascending (1) and descending (2) satellite directions in a 4-year period. There is an evident difference in autocovariance functions for different directions. The correlation radius for

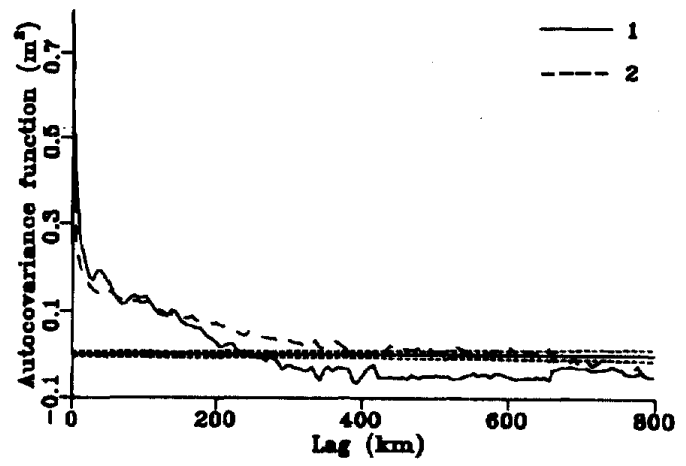

Fig. 2. Autocovariance functions for ascending (1) and descending (2) tracks. Dotted line shows $95 \%$ confidence level for not correlated values 


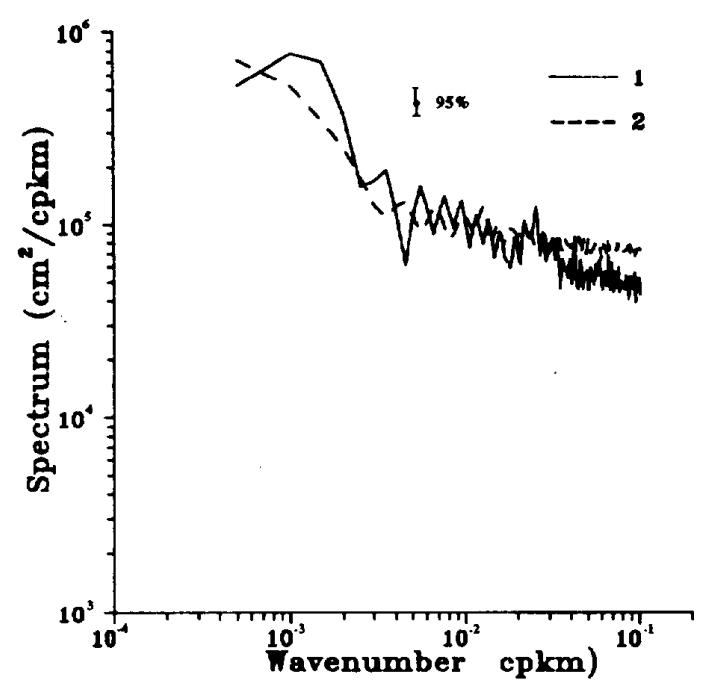

Fig. 3. Along-track wave number spectra for ascending (1) and descending tracks computed as the Fourier transform of covariance function

ascendant tracks $(200 \mathrm{~km})$ differs from that one for the descendant tracks $(300 \mathrm{~km})$.

We use Fourier transform of autocovariance functions to compute along-track wavenumber spectra. The resulting spectra are displayed in Fig. 3. Low-frequency parts of the spectra are 'red'. The spectra are becoming 'white' for the wave lengths shorter than $200-300 \mathrm{~km}$, apparently because of the instrument noise which is about $0.7-0.8 \mathrm{~m}$. There is a broad spectral 'bump' for the ascendant track spectrum, corresponded to wave lengths from 500 to 1000 $\mathrm{km}$, which is absent for the descendant spectrum.

At wavelengths longer than $250-300 \mathrm{~km}$ the spectra begin to level off. This point likely relates to the firstmode Rossby radius of deformation. The length scales 150-300 are typical for baroclinic instability disturbances.

The method of maximum entropy was used in addition to standard procedure of spectral analysis. The results are presented in Fig. 4. The general spectral structure is the same as in Fig. 3 but the difference in the spectra of the ascending and descending tracks has become more obvious, especially for high frequencies. This feature is very peculiar as the high frequency part of spectra is supposed to be determined by the instrument noise. It could be probably explained by specific noise properties of the altimetry samples ( $1 \mathrm{sec}$ ). In this case the maximum entropy spectral model must filtrate some of the instrument noise and difference in high-frequency sea level components for two tracks is better seen.

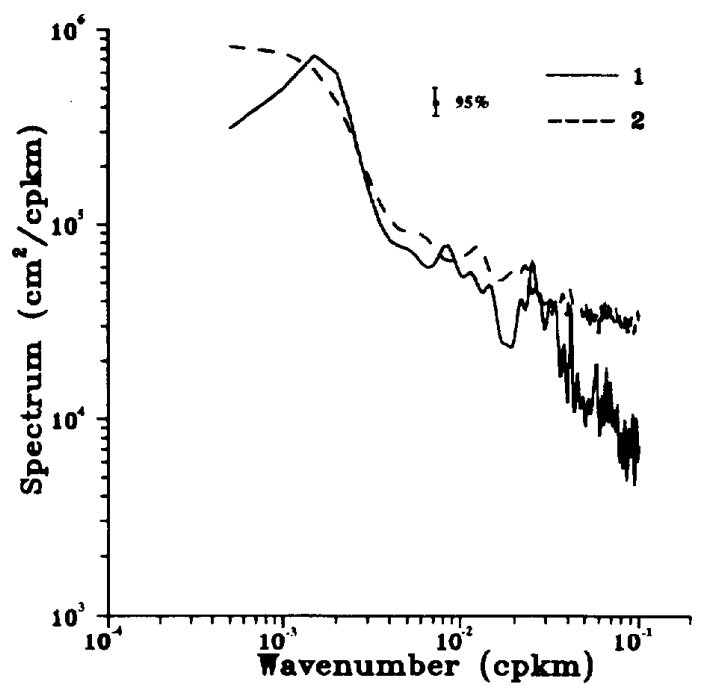

Fig. 4. Along-track wave number spectra for ascending (1) and descending (2) tracks computed by the maximum entropy method

\section{DISCUSSION}

Comparing the map of satellite tracks and the typical current picture in the chosen region (see Fig. 1) one may conclude that the ascending tracks approximately correspond to the mean direction of the North Atlantic Current, while descending tracks in fact go across the main flow. The corresponding statistical characteristics for the two types will differ first of all due to the anisotropy of a stochastic field (instant) of the ocean level deviation caused by purely dynamic reasons of the frontal zone of the North Atlantic Current.

These results agree well with results presented in [12 ]. Using GEOSAT altimetry data for 2 years Le Traon et al. showed the distinct difference between ascending and descending track spectra for the Gulf Stream area and supposed that the difference could be related to the way Gulf Stream meanders develop.

$\mathrm{Fu}$ [5] suggested to divide the whole area of the ocean into two main categories, according to the sea level energy in the mesoscale frequency band: (1) the 'high-energy area' which is close to the major current systems; (2) the 'low-energy area' which usually is remote from the regions of strong ocean currents.

The existence of the 'bump' in the ascending spectrum in our study is a sign of 'high-energy area,' as the smooth monotonic character of the descending spectrum is typical for 'low-energy areas.' 
Thus, the frontal zones are zones of anisotropic sea level mesoscale variability due to waveguide mechanism. This mechanism could be explained as trapping of wave or disturbance energy by frontal gradients of density and potential vorticity. So disturbances are propagating along main current ("frontal boundary zone" [13]) and attenuate with distance from the current axis.

\section{REFERENCES}

[1] T. Godbey, "Oceanographic satellite radar altimetry and wind sea sensor," in Oceanography from Space, Rep. 65-10, Woods Hole Oceanograph. Inst., Woods Hole, Mass., 1965.

12] M. Wolf, "Direct measurements of the Earth's gravitational potential using a satellite pair," J. Geophys. Res., vol. 74, No. 22, 1965 , pp.5295-5300.

[3] H. R. Stanley, "GEOS3 Project," J. Geophys. Res., vol. 84, No. B8, 1979, pp. 3779-3783.

[4] R. H. Rapp, "Geos 3 data processing for the recovery of geoid undulations and gravity anomalies," J. Geophys. Res., vol. 84, No. B8, 1979, pp. 3784-3792
[5] L.-L. Fu, "On the wave spectrum of oceanic mesoscale variability observed by SEASAT altimeter," J. Geophys. Res., vol. 88, No. C7, 1983, pp. 4331-4341.

[6] Ye. A. Kulikov, V. G. Pavlenko, S. S. Lappo and A. B. Rabinovich, "Second Soviet-American Expedition to study tsunamis in the open ocean," Oceanology, vol. 19, No. 2, 1979, pp. 235-236.

[7] H. M. Byrne and P. R. Pullen, "SEASAT-derived ocean surface topography: Comparison with coincident Kuroshio hydrographic data," J. Geophys. Res., vol. 88, No. C4, 1983, pp. 2621-2625.

[8] E. W. Schwiderski, "Ocean tides, I, Global ocean tidal equations," Marine Geodesy, vol. 3, 1980, pp. 161-218.

[9] E. W. Schwiderski, “Ocean tides, II, A hydrodynamical interpolation," Marine Geodesy, vol. 3, 1980, pp. 219-255.

[10] E. W. Schwidersk1, "On charting global ocean tides," Rev. Geophys. Space Phys., vol. 18, 1980, pp. 243-268.

[11] Ye. L. Macedonsky, V. B. Nepoklonov, and L. I. Zadorozhko, "Modelling of Earth gravity field for correction of measuring and navigation instruments," Reviews on Ship-Building Technics, Central Sci. Res. Inst. "Rumb, " St. Petersburg, 1992 (in Russian).

[12] P. Y. Le Traon, M. C. Rouquet, and C. Boissier, "Spatial scales of mesoscales variability in North Atlantic as deduced from Geosa data," J. Geophys. Res., vol. 95, No. C1 1, 1990, pp. 20267-20285.

[13] V. V. Yefimov, Ye. A. Kulikov, A. B. Rabinovich and I. V. Fine, Ocean waves in boundary regions, Leningrad: Gidrometeoizdat, 1985 (in Russian). 